\title{
Tecnologias sociais como políticas públicas de inclusão social
}

\author{
COSTA, Adriano Borges (Org.). Tecnologia Social e Políticas Públicas. São
} Paulo: Instituto Polis; Brasília: Fundação Banco do Brasil, 2013.

Bruna Mendes de Vasconcellos

Programa de Pós-Graduação em Política Científica e Tecnológica da Universidade Estadual de Campinas

(Unicamp)

O livro "Tecnologia Social e Políticas Públicas", organizado por Adriano Borges Costa, tem como objetivo principal avançar na reflexão sobre políticas públicas que adotam a tecnologia social como ferramenta para minimizar processos de exclusão socioeconômica. Através da análise crítica de uma série de experiências em andamento no país, de ações governamentais que fazem uso de diferentes tecnologias sociais como estratégia de intervenção e promoção da inclusão social, o livro contribui sobremaneira como subsídio para o aprimoramento de futuras políticas públicas de inclusão social.

A publicação é organizada em uma parceria da Fundação Banco do Brasil (FBB) e do Grupo de Análise de Políticas de Inovação da Unicamp (GAPI). Refletindo a considerável experiência teórica e prática das instituições na temática proposta, os casos apresentados são análises contundentes, que articulam os referenciais teóricos da Tecnologia Social e de análise de políticas, com o conhecimento empírico da realidade analisada e do funcionamento do sistema estatal.

Além de um capítulo teórico inicial e dois capítulos analíticos finais, ao longo do livro são apresentadas oito experiências de políticas públicas baseadas no uso de tecnologias sociais, a grande maioria sendo no setor rural e muitas no Semiárido brasileiro, a saber: Programa 1 Milhão de Cisternas (P1MC), fundos rotativos de produção, tratamento de resíduos eletrônicos, educação no campo (pedagogia da alternância), horta urbana comunitária, Programa Água Doce (dessalinizadores), fossas sépticas para tratamento de esgoto e a agroecologia (PAIS).

Existem duas questões centrais que guiam a organização das análises para todos os estudos de caso. Uma delas é a forma como se constroem e implementam as políticas públicas, quais são os atores envolvidos, suas formas de articulação e 
papéis que ocupam na definição e execução das políticas. Outra é a preocupação em compreender como essas políticas de reaplicação de tecnologias sociais poderiam ganhar escala, sem que isso implique em perdas nos processos sociotécnicos; ou seja, como ampliar as ações e, ainda assim, garantir o empoderamento dos(as) usuários(as) finais. No pano de fundo dessas análises há uma preocupação em compreender como opera a participação social em cada uma das etapas de constituição das experiências, seja na definição das políticas públicas ou como atores-chave nos processos sociotécnicos de construção de tecnologias. Essa ideia está ancorada nas referências teóricas que dão subsídio ao livro.

A tecnologia social é compreendida nessa publicação como um conceito que, apesar de ter suas origens na ideia de Tecnologia Apropriada, incorpora as contribuições dos Estudos Sociais da Ciência e da Tecnologia e, portanto, critica a suposta neutralidade da ciência e tecnologia e refuta o determinismo tecnológico, compreendendo que as rotas tecnológicas são socialmente determinadas (cap. 1). Assim, entende a construção tecnológica como um processo definido pelas relações estabelecidas entre diferentes atores sociais e que, portanto, não pode ser visto como um artefato isolado. A tecnologia social é vista como um processo de construção de tecnologias a partir de uma lógica mais sustentável e solidária, voltada para a inclusão social, e que conta, necessariamente, com o envolvimento e a participação dos(as) usuários(as) finais na sua definição.

Por sua vez, o referencial de análise de políticas, no qual se baseiam as análises do livro, busca compreender as mudanças que ocorreram na administração pública ao longo da história recente e entender as novas formas de funcionamento sob as quais opera. Com a quebra do paradigma do Estado do bem-estar social, a partir dos anos 1990, configuram-se novos arranjos institucionais, fundando-se as ações governamentais, cada vez mais, no estabelecimento de parcerias e alianças entre Estado e sociedade civil. Entendendo esse cenário modificado, o conceito de política pública adotado foge de análises centradas no Estado devido às suas limitações para os propósitos da presente pesquisa, centrando suas atenções nas novas formas de articulação que vem se estabelecendo entre Estado e organizações da sociedade civil (cap. 11).

Nesse sentido, a primeira experiência apresentada pelo livro, aquela da construção do Programa 1 Milhão de Cisternas (cap. 2), talvez possa ser vista como o estudo de caso mais complexo, de maior amplitude. Ela merece destaque pelo protagonismo de organizações da sociedade civil no processo de definição da política como um todo, gerando também relevante envolvimento das comunidades na construção da tecnologia social e permitindo a definição de processos sociotécnicos com empoderamento dos(as) usuários(as) finais. O Programa em questão tem como principal objetivo a instalação de cisternas para armazenamento de água em casas de famílias de comunidades rurais do Semiárido sem acesso a água em quantidade suficiente ou em condições adequadas para o 
consumo humano. Desde 2003 vem sendo executado pelo Ministério do Desenvolvimento Social (MDS) e pela Associação do Semiárido Brasileiro (ASA).

O protagonismo da ASA na construção do P1MC traz subsídios analíticos para entender os desafios e possibilidades da articulação entre Estado e organizações da sociedade civil na formulação e execução de políticas públicas baseadas em tecnologia social. A associação é uma rede que existe desde os anos 1990, composta hoje por mais de 700 organizações da sociedade civil nordestina. Problematizando as soluções apresentadas à população do semiárido, sempre baseadas em grandes obras de combate a seca, a ASA vem consolidando um discurso e propostas de políticas de convivência com o Semiárido, que visam melhorar as condições de permanência das famílias na região a partir de soluções simples e baratas, mas com alto impacto social - como é o caso do P1MC. Nesse sentido, a sociedade civil tem papel ativo na definição do problema público, que passa a ser a base para formular a política. O papel da ASA, ao mudar o problema de combate a seca para convivência com a seca, instaura uma nova compreensão do problema, reformulando o norte organizador das políticas, ou seja, o problema público (cap. 2).

Para além da formulação do problema e da política pública, a ASA é também seu agente executor. É quem faz a ponte entre o governo e as famílias e comunidades que recebem as cisternas. Nesse contexto, cumpre o papel de garantir um diálogo entre as diferentes lógicas da burocracia estatal e aquela da sociedade civil. Segundo as análises de Costa e Dias (cap. 2), essa articulação garantiu processos sociotécnicos com apropriação da tecnologia pelas famílias, havendo certas adequações sociotécnicas no projeto inicial quando necessárias, e desencadeando um processo de empoderamento das mesmas, levando ao seu engajamento social e político nas comunidades. Assim, a articulação entre Estado e sociedade civil na definição e execução das políticas públicas de tecnologia social se mostra funcional ao permitir que as tecnologias ganhem escala sem que se perca o foco nos processos e no envolvimento dos(as) usuários(as).

Nesse sentido, a análise destaca também a importância de compreender a tecnologia social como um processo e não como um produto, uma vez que as experiências analisadas indicam que, com frequência, os processos de construção são mais relevantes que os resultados diretos obtidos, que os produtos gerados. É através dos processos sociotécnicos que se alcançam as dinâmicas de empoderamento e de inclusão social almejadas pelas políticas. As tentativas do governo de acelerar o programa e instalar cisternas de plástico, gerando mais custos e sem qualquer tipo de envolvimento das comunidades, foi fortemente criticado pela ASA na tentativa de garantir uma política com real participação das famílias beneficiadas.

Esses processos de conflito e negociação entre MDS e ASA caracterizam esses mais de 10 anos de construção e implementação da política. $O$ artigo não se refuta 
a apresentar os processos conflituosos que caracterizam essa relação, mas destaca como a ASA tem conseguido articular a sociedade civil para pressionar o governo e superar os momentos de ruptura e instabilidade na permanência do Programa. Assim, o artigo ressalta a importância dessa experiência, uma vez que essa tem sido uma política exitosa: já foram instaladas mais de 500 mil cisternas e melhoradas as condições das famílias do Semiárido brasileiro. Para os autores, o envolvimento da ASA em todas as etapas de construção dessa política, desde a própria definição do problema, a construção da solução, a proposta da política e seu envolvimento na execução, são as chaves para seu sucesso.

A experiência positiva dessa articulação entre Estado e sociedade civil é o que leva Ribeiro e Jesus, as autoras do terceiro capítulo, sobre a organização dos Fundos Rotativos de Produção, a destacar esse como um caso que merece atenção, já que é uma proposta que surge a partir da sociedade civil e poderia ganhar força em sua articulação com o Estado (cap. 3). Os Fundos Rotativos são formas de poupança e articulação comunitária que visam garantir recursos para a organização da produção. São autogeridos pelas famílias integrantes, que fazem as doações iniciais para seu funcionamento, seja com recursos monetários, em produtos (como sementes e animais), seja com serviços. Muito usados nas comunidades rurais do Nordeste desde os anos 1990, como fruto também de formas mais tradicionais de organização na região, atualmente são utilizados também para financiar a implementação de tecnologias sociais, como é o caso das cisternas. A ASA tem mapeado ao redor de 1000 experiências desse tipo no Semiárido.

Esses Fundos são caracterizados pela sua informalidade. São baseados nas relações de proximidade e na auto-organização dos agricultores. Assim, as autoras destacam que a formalização jurídica e a criação de procedimentos formais de prestação de contas, no caso da constituição de uma política pública de fomento a essas iniciativas, certamente, implicaria em dificuldades para o funcionamento das mesmas. Nesse sentido, chama-se atenção para os riscos de consolidação de uma política pública bem estruturada, mas que, por essa mesma razão, dificulta a permanência dos formatos mais informais manejados pelas comunidades e sua autonomia. A experiência do P1MC é, pois, um exemplo de como as articulações entre a sociedade civil organizada e o Estado podem ser uma ferramenta importante para o diálogo entre diferentes lógicas.

No estudo de caso sobre tratamento de resíduos eletrônicos, o papel do Movimento Nacional de Catadores na construção do Plano Nacional de Resíduos Sólidos, que sanciona a necessidade de integração dos catadores na gestão dos resíduos, é mais um exemplo trazido pelo livro do envolvimento de organizações da sociedade civil na definição da política pública. A definição dessa política reverbera no país como um todo e assenta as bases para que os catadores do Sul reivindiquem sua participação na cadeia de tratamento dos resíduos eletrônicos (REEE). A partir de uma tecnologia montada pelos próprios catadores, o projeto visa ao desenvolvimento de tecnologias simples, baratas, de fácil acesso e com 
reaplicação. Portanto, uma tecnologia acessível aos catadores para viabilizar um sistema de gestão dos REEE com sua devida integração. A tecnologia social se torna, nesse caso, um meio necessário para viabilizar a política pública com efetiva inserção dos catadores (cap. 4).

Outro caso analisado pelo livro é o Programa Água Doce. Assim como o P1MC, é implementado no Semiárido brasileiro e prevê minimizar as dificuldades da escassez de água. No entanto, nesse caso investe-se na construção de dessalinizadores que possam tornar a água do solo adequada ao consumo humano (cap. 7). A questão central colocada por esse estudo de caso é que essas tecnologias já foram implantadas no passado, mas, em sua maioria, caíram em desuso. A novidade do programa atual foi tentar conciliar elementos de tecnologia social à tecnologia convencional já existente, procurando-se na autogestão das máquinas a solução para o abandono das mesmas. A nova concepção do programa articula diferentes atores do governo e da sociedade civil, para viabilizar suas ações e gerar empoderamento comunitário, que garanta o funcionamento da política que, segundo avaliação dos autores, Costa e Abreu, tem se mostrado efetiva até o momento.

No entanto, segundo os(as) autores(as), o Programa Água Doce corre risco semelhante ao P1MC: possui metas de ampliação que podem interferir diretamente no papel das comunidades no processo. Nos dois programas, para alcançar números mais significativos de implementação das tecnologias, há propostas de aquisição de tecnologias convencionais que seriam instaladas sem qualquer integração com as comunidades beneficiárias. Assim, uma das questões iniciais colocadas pelo livro se destaca: de que maneira ganhar escala sem colocar em risco o bom funcionamento dos sistemas? De que forma ampliar a tecnologia social e garantir o empoderamento e a autogestão de sistemas sociotécnicos? Os exemplos trazidos pelo livro indicam que essa ainda é uma tarefa difícil. Metas muito ousadas de ampliação parecem levar a uma desvalorização dos processos onde ocorre efetivo empoderamento comunitário. E centrar a atenção nos produtos e resultados enfraquece os laços de articulação e participação dos diferentes atores, causando perdas no potencial da tecnologia social para alavancar processos mais amplos de inclusão.

Nesse sentido, duas experiências de fossas sépticas, alternativas às tradicionais, são analisadas na publicação com vistas a dar subsídios ao processo de formulação de políticas públicas de saneamento rural. Os modelos (de fossas sépticas) desenvolvidos pela Embrapa, em São Carlos, e outro implementado em Caratinga (MG), com o apoio do poder público e da Organização Povo que Luta, são apresentados como potenciais tecnologias sociais, que poderiam contribuir para sanar o déficit de domicílios inseridos na rede de tratamento de esgotos - que atinge apenas 5,7\% das casas no meio rural no Brasil (cap. 8). Além de destacar diferenças técnicas entre as tecnologias apresentadas, Serafim e Dias salientam que o potencial dessas tecnologias, como ferramenta para a política pública, só poderia 
efetivar-se mediante a construção de um arranjo que permita o envolvimento comunitário, a gestão das adequações técnicas em conformidade com as especificidades locais e a promoção de processos educativos a partir do saneamento.

A fragilidade das políticas públicas, em que há débeis laços de articulação de diferentes atores e pouco protagonismo de beneficiários(as), é evidenciada por alguns dos casos apresentados no livro. No caso do programa de hortas urbanas instaurado na cidade de Maringá (PR) (cap. 6), o papel (em alguma medida, ainda, passivo) da comunidade receptora da política dificulta o seu fortalecimento. A comunidade se envolve apenas na gestão das hortas, e a rede de apoio articulada pela política se mostra limitada. Na avaliação de Serafim e Dias, a segurança alimentar no município, através da instauração de hortas nos seus bairros periféricos, requer o enfrentamento desses problemas.

Algumas outras dificuldades que surgem no processo de implementação de políticas públicas baseadas em tecnologia social são apresentados no estudo sobre as Casas Familiares Rurais. É uma experiência de escolas do campo, em Igrapiúna (BA), que conta com apoio da Fundação Odebrecht. Aí se utiliza a metodologia da pedagogia da alternância. $O$ alto custo das escolas, a falta de profissionais preparados para lidar com a proposta e, também, uma barreira institucional (expressa na resistência em aderir a novas propostas educativas) aparecem, nesse caso, como limitantes à sua reaplicação enquanto política pública (cap. 5).

Fugindo de uma lógica analítica centrada no Estado, os estudos de caso reforçam a visão inicialmente apresentada pelo livro sobre uma concepção híbrida do Estado e das políticas públicas. O reconhecimento do protagonismo da sociedade civil e dos atores locais, em todas as etapas do processo de definição e implementação das políticas, garante maior viabilidade e êxito às políticas. Dias e Borges mostram (cap. 10) que o apoio público requer que se entendam e respeitem as diferentes lógicas de funcionamento do Estado e da sociedade civil, dando as articulações bem construídas sustentação às próprias políticas. Cada capítulo do livro apresenta um mapa com os atores e vínculos que ajuda a entender as relações estabelecidas.

O desafio de alcançar escala na implementação de tecnologias sociais parece de mais difícil saída. As análises indicam, em todos os casos, que o sucesso sociotécnico de um artefato não está relacionado aos resultados ou ao produto em si, mas à autogestão e ao envolvimento das comunidades no processo de construção das tecnologias, gerando empoderamento dos(as) usuários(as) ao longo do processo e abrindo as portas para uma maior inserção política e social no seu território. O caso de maior escala apresentado é o do P1MC. Apesar do evidente sucesso da política, as propostas de ampliação das metas parecem colocar em risco os processos sociotécnicos, instaurando uma lógica difusionista. Assim, o estudo dessas experiências aponta para uma contradição inerente ao desafio de se 
construir uma ação pública, baseada em tecnologia social em escala, sem que ocorram perdas no empoderamento sociotécnico das comunidades envolvidas. A ampliação da escala parece seguir sendo um dos grandes desafios. Para Costa e Dias (cap. 10), algumas pistas para superar essa questão residem na construção de novas formas de relação entre Estado e sociedade civil.

Para esses autores, fortalecer os vínculos entre sociedade civil e poder público são passos importantes. Tais vínculos podem ser favorecidos por novas formas jurídicas que reconheçam o papel das ONGs como instituições importantes nessa mediação. E, também, o dos denominados "burocratas de rua", os agentes do Estado mais diretamente em contato com as comunidades. Ambos podem transitar mais facilmente entre as duas lógicas por meio de uma melhor comunicação. É como o Estado pode reunir mais subsídios para garantir as adequações sociotécnicas necessárias e as reformulações possíveis nas políticas.

A publicação destaca ainda o incipiente papel das Políticas de Ciência e Tecnologia voltadas para a tecnologia social. Elas têm um foco extremamente cientificista. Recentemente, incorporaram as demandas das empresas pela força que ganharam os discursos pró-inovação. Portanto, seguem uma lógica de investimentos que não privilegia a inclusão social e a sustentabilidade no país (cap.10). Nesse sentido, há uma lacuna a ser preenchida. $E$ há recursos a serem disputados para a consolidação de políticas de C\&T para a tecnologia social, visando não apenas sua construção e implementação, mas também pesquisas de monitoramento e avaliação que possam fortalecer as ações existentes.

Por fim, os autores salientam que as experiências estudadas dificilmente podem ser consideradas como componentes de uma política pública, devido, em especial, à instabilidade jurídica e operacional das ações que foram visitadas. As descontinuidades causadas pela lógica de "projetos" são os maiores problemas encontrados nos casos selecionados. Destaca-se, no encerramento do livro, que a estrutura jurídica e a burocracia estatal não estão preparadas para estabelecer as parcerias com as organizações da sociedade civil - que, segundo as análises presentes na publicação, são as formas mais adequadas de viabilizar políticas públicas baseadas em tecnologias sociais. O envolvimento da sociedade civil durante todas as etapas de construção da política pública e ao longo do processo de definição da tecnologia social é crucial. Portanto, para o sucesso dessas políticas públicas, viabilizar a participação parece ser o grande desafio colocado pelas análises contidas nessa publicação.

A publicação reúne um conjunto de estudos de caso selecionados, que contribuem para uma reflexão profunda sobre os caminhos a serem trilhados na definição de uma política pública baseada em tecnologia social. O livro é, portanto, um guia essencial para organizações da sociedade civil, gestores e acadêmicos engajados com o tema da tecnologia social, especialmente, aqueles que visualizam a importância de sua inserção como política pública. 
Por fim, Renato Dagnino (cap. 11) afirma que a relevância deste livro também está na postura da Fundação Banco do Brasil (FBB), que vem investindo na construção e concepção de políticas públicas para a tecnologia social. Essa publicação tende a tornar-se, enfim, um grande marco político-acadêmico sobre a tecnologia social.

Endereço para correspondência:

Bruna Mendes de Vasconcellos - brunavasconcellos@gmail.com Rua João Pandiá Calógeras, 51 - Cidade Universitária Zeferino Vaz 13084-000 Campinas/SP, Brasil 